\title{
PENGEMASAN TARI GUEL DALAM BENTUK KARTU POS SEBAGAI MEDIA PEMBELAJARAN
}

\author{
Suciati Simah Bengi ${ }^{1}$, Yusnizar Heniwaty ${ }^{2}$, Dilinar Adlin ${ }^{3}$ \\ Prodi Pendidikan Tari/ Fakultas Bahasa dan Seni/ Universitas Negeri Medan \\ Jalan Willem Iskandar Pasar V Medan Estate 20221, Sumatera Utara-Indonesia \\ 1.
}

\begin{abstract}
This study discusses Guel dance learning media created in the form of postcards. Aims to be able to direct students in identifying, appreciating, and expressing dances of the Gayo area, especially Guel dance. Theories used in the research of packaging theory according to Cahyorini and Rusfian (2011: 28), theory of learning media according to Heinich in Susilana (2016: 06), and graphic media theory according to Susilana and Riyana (2016: 14) Packaging is a theory used for graphic design, in terms of producing the product, and the image media in the form of postcards used to make Guel dance material as a learning medium. The time of the study was conducted from August to October 2017. The research site was at Sanggar Renggali Jalan Merah Mege Hakim Bale Bujang Laut Tawar, Central Aceh District. The population of several artists Gayo and all members of Sanggar Renggali because learning Guel dance is a dance learning materials in schools in Takengon and Samples are 2 people Gayo artists and 2 dancers dance Guel. Data collection techniques include observation, interview, literature study, and documentation, and then analyzed by qualitative descriptive method. Based on research that has been done Guel dance is a tradition dance Gayo community that has been used as learning materials in the schools of Middle Secondary in Central Aceh district. Guel dance which is packed in the form of postcards as a medium of learning with menggunkana first step of planning is preparing the material, determining the location, selection of dancers, and prepare the facilities and infrastructure. The second step of implementation is taking photos, editing process, then the last step is the completion of postcards and final writing. And produces packaging of learning media of Guel dance that is in the form of postcard.
\end{abstract}

Keywords: Packaging, Guel Dance, Postcard Media

\section{PENDAHULUAN}

Sekolah merupakan wadah dimana pendidikan dapat ditempuh, dengan peserta didik yang dapat menimba berbagai macam ilmu. Dalam proses belajar mengajar guru dapat menggunakan metode dan media pembelajaranuntuk memperlancar serta mempermudah dalam memberikan materi pembelajaran. Pada umumnya metode yang dilakukan menggunakan metode demonstrasi. Berdasarkan dari observasi yang dilakukan peneliti, sebagian sekolah-sekolah di Kota Takengon masih menggunakan proses pentransferan dengan cara pembelajaran terpusat pada guru, contohnya metode demonstrasi karena metode ini sering digunakan sekolah-sekolah di Kota Takengon terutama pada pembelajaran seni tari. Pada silabus seni tari kelas VII semester 2 kompetensi dasar yang dipelajari adalah mengidentifikasi jenis karya seni tari berpasangan/kelompok daerah setempat yang dimana selama ini tari yang dipelajari adalah tari Guel. Oleh sebab itu acuan peneliti dalam mengemas tari Guel dalam bentuk kartu pos adalah silabus dan RPP yang menjadi pedoman dalam proses belajar mengajar.

Aceh merupakan daerah yang menerapkan materi tari daerah dalam mata pelajaran seni tari, materi tari yang sering dipelajari seperti tari Saman, tari Guel,tari Ranup Lampuan, dantari Seudati. Dibagian besar sekolah-sekolah di kota Takengon menggunakan tari Guel sebagai materi pembelajaran. Tari Gueldigunakan sebagai materi pelajaran pada Siswa 
Sekolah Pertama di Takengon yaitu mempelajari Tari Guel sebagai tari kelompok daerah setempat siswa akan mengetahui apa yang ada di daerah tinggalnya dan menghargai peninggalan budaya serta dapat meneruskan budaya tersebut untuk kehidupannya kelak. Berdasarkan persoalan diatas perlu kiranya menyusun media-media pembelajaran sebagai alternative dalam PBM. Media kartu pos dianggap memperjelas materi pelajaran siswa, agar cepat memahami materi yang disampaikan oleh guru. Media kartu pos juga dapat dijadikan solusi dalam ketidak memadainya media pembelajaran di sekolah. Media kartu pos ini juga tidak menggunakan fasilitas yang harus mendukungnya seperti media audio visual yang menggunakan laptop dan LCD proyektor karena kartu pos ini berbentuk gambar yang telah dicetak dan sangat praktis untuk guru dalam membawa kemana saja. Media kartu pos dapat digunakan guru dalam mengajar dan dapat digunakan oleh siswa dalam proses belajar. Sehingga media kartu pos dapat digunakan oleh guru dan siswa. Media kartu pos juga akan menarik perhatian siswa dengan adanya gambar-gambar dari Tari Gueldan warna-warna yang menarik perhatian siswa, dengan adanya gambar-gambar pada kartu pos ini juga memudahkan guru dan siswa dalam membedakan gambar-gambar pada kartu pos itu sendiri.

Dalam berapresiasi seni siswa dapat melihat secara langsung tari Guel didalam media kartu pos sehingga siswa dapat mengapresiasi dengan baik materi Tari Guel. Selain itu dalam berkreasi seni siswa juga dapat melihat contoh tari Guel secara langsung di media kartu pos dan merangsang fikiran siswa terhadap kreativitas lain yang akan ia buat dalam memahami tari Guel.
Tujuan yang harus dicapai dalam penelitian ini adalah :

1. Mengemas tari Guel dalam bentuk kartu pos sebagai media pembelajaran.

\section{LANDASAN TEORI}

Untuk membahaspengemasan tari Guel dalam bentuk kartu pos sebagai media pembelajaran, menggunakan teori pengemasan, media pembelajaran yang menggunakan media grafis yang berbentuk kartu pos.

\section{METODOLOGI}

\section{Lokasi dan Waktu Penelitian}

Lokasi penelitian ini dilakukan di Sanggar Ranggali Jalan Merah Mege No. 285 Takengon, Aceh Tengah. Waktu penelitian ini dilakukan di bulan Agustus Oktober 2017.

\section{Populasi dan Sampel \\ Populasi}

Populasi dalam penelitian ini adalah senimanseniman Gayo di Takengon.

\section{Sampel}

Adapun sampel dalam penelitian ini, yang akan menjadi subjek penelitian adalah 3 seniman Gayo, dan dua diantaranya menjadi model gerak tari Guel di dalam kartu pos.

Teknik Pengumpulan Data yang dilakukan adalah sebagai berikut:

1. Observasi

2. Wawancara

3. Dokumentasi/Perekaman

4. Studi Kepustakaan

Teknik Analisis Data 
Data yang diperoleh dari hasil observasi, wawancara, dokumentasi dan studi kepustakaan yang telah dilakukan peneliti akan diolah dan dianalisis dengan teliti. Hasil olahan dan analisis tersebut disusun secara sistematis dengan metode deskriptif kualitatif sehingga hasil penelitian dapat dilihat dalam bentuk laporan ilmiah atau skripsi.

\section{PEMBAHASAN}

\section{Sanggar Renggali Takengon}

Sanggar Renggali Takengon adalah salah satu sanggar tari yang ada di Kota Takengon di daerah Dataran Tinggi Gayo. Sanggar ini pertama kali dibangun pada tahun 2005 dengan dipimpin kepala sanggar yaitu bapak Teuku Aga Dewantona. Sanggar ini beralamat di Jalan Merah Mege Nomor 285, Hakim Bale Bujang, Lut Tawar Kabupaten Aceh Tengah.

Sanggar Renggali juga merupakan sanggar tari yang berkembang di daerah Gayo khususnya daerah Kota Takengon. Pada dasarnya sanggar Renggali ini merupakan sanggar Gayo di kota Takengon dan masih membudayakan tari-tari Gayo khususnya tari Guel, sehingga penari-penari tariGuel maupun tari-tari Gayo lainnya di sanggar Renggali terbukti memilki banyak prestasi dalam bidang kesenian.

Sanggar Renggali ini juga memiliki banyak prestasi dalam bidang kesenian, bukan prestasi dibidang tari saja melainkan dibidang seni musik. Salah satu prestasi yang telah diraih sanggar tersebut yaitu masuk dalam salah satu dari tiga sanggar mewakili kesenian Aceh, pada acara tingkat nasional yakni Penas Kontak Tani Nelayan Andalan (KTNA) XV di Kota Banda Aceh. Karena prestasi dan kemampuan Sanggar Renggali dibidang kesenian ini, maka penulis memilih Sanggar Renggali untuk tempat penelitian.

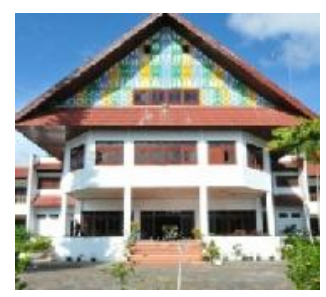

Gambar: Tampak Depan Sanggar Renggali.

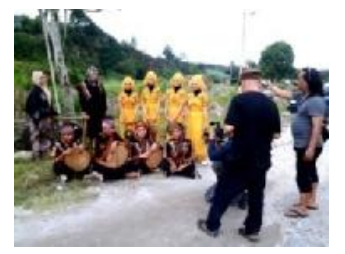

Gambar : Kegiatan di Sanggar Renggali

\section{Suku Gayo Aceh Tengah}

Suku Gayo adalah salah satu suku penduduk asli Indonesia, mereka bermukim di wilayah poros Provinsi Aceh, luasnya dalam sebutan Sebujur Acih Selintang Batak. Sebagai salah satu penduduk bangsa Indonesia suku Gayo mempunyai budaya yang berbeda-beda dengan suku-suku lain. Pembahagian wilayah menjadi kabupaten dengan pemerintahan sendiri dan menyebar sedemikian rupa sehingga terjadi perbedaan budaya, serupa tapi tak sama. Adapun pembagian penduduk Gayo tersebut yaitu Gayo Deret untuk kawasan Linge, Isak, Gayo Lut untuk kawasan Danau Lut Tawar, Gayo Lues untuk kawasan Belang Kejeren, Gayo Lukup Serbejadi untuk kawasan Aceh Timur dan Kalul di Aceh Tamiang.

Tari tradisional merupakan salah satu kesenian yang merupakan kekayaan daerah dataran tinggi Gayo selain sumber alam dan mata pencaharian masyarakat Gayo seperti tari Saman, tari Guel, tari Pukat, tari Tuak Kukur, tari RanupLampuan, dan tari Seudati. Adapun 
tari-tari tersebut merupakan tari tradisi masyarakat Gayo dan masyarakat Aceh.

\section{PengemasanTari Guel Dalam Bentuk Kartu PosSebagai Media Pembelajaran}

1. Perencanaan

- Menyiapkan materi: Adapun tahap-tahap dalam menyiapkan materi antara lain :

- Identifikasi Gerak tari Guel

- Pembagian babak dalam tari Guel

1) Babak Ras

Gerak-gerak yang termasuk dalam babak Ras yaitu:

a. Gerdak Papan (Gertak Papan)

b. Semar Kalang (Burung Elang Mencakar)

c. Kepur Nunguk (Kipas Sayap Burung Pungguk)

d. Jangin (Memohon Ijin)

2) Babak Sining Lintah (Lintah Berenang)

3) Babak Munatap (Proses Membangunkan Gajah)

Gerak-gerak yang termasuk dalam babak Munatap yaitu:

a. Salam Semah (Salam Sembah)

b. Munatap Kanan

c. Munatap Kiri

d. Munatap Gajah

4) Babak Redep/Dep (Berdiri)

5) Babak Cincang Nangka (Bergembira)

Gerak yang terdapat pada babak ini yaitu:

a. Runcang (Bebas)

6) Babak Ketibung(Mengiring Gajah)

- Penetapan Lokasi

Di Sanggar Renggali Takengon Jalan Merah Mege, Hakim Baleng Bujang Kabupaten Aceh Tengah.
- Pemilihan Penari/ Model2 penari Guel Sanggar Renggali.

- Menyiapkan sarana dan prasarana

- Kamera Canon eos 70 D

- Lensa 18-200 for Canon

- Lampu (plash) merk Youno max II for Canon

- Komputer PC

- $\quad$ Editing Corel X6

2. Pelaksanaan

- Pengambilan Foto

- Proses Editing

3. Evaluasi

- Penyelesaian kartu pos

- Penulisan akhir

Hasil Kemasan Tari Guel Dalam Bentuk Kartu Pos Sebagai Media Pembelajaran.

Sampul Kartu Pos : Sampul diambil dari seorang penari Guel yaitu Teuku Aga Dewantona, dengan memakai motif baju Kerawang gayo dan sekaligus sebagai peraga tari Guel dalam kartu pos ini. ini.

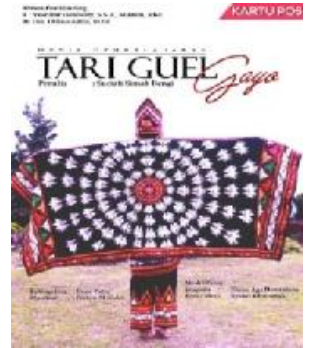

Fhotografer : Deno Putra, Peraga Tari Guel II : Syukri Chairullah, Desainer: Wahyu M Rizki

\section{Kata Pengantar :}

Berisi tentang Pengantar Kata yang dibuat oleh penulis sebagai kata pembuka dalam kartu pos ini, adapun isinya dpat dibaca langsung dalam kartu pos yang sudah dikemas.

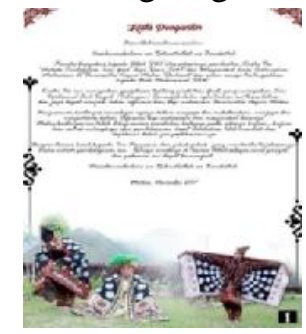




\section{Daftar isi :}

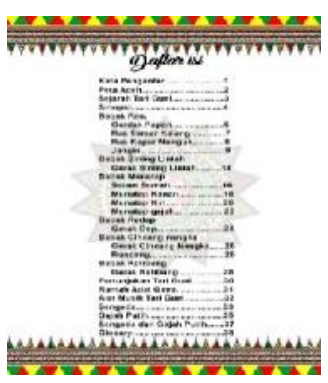

Peta Aceh Tengah :

Dalam kartu Pos ini penulis meletakkan Peta Aceh Tengah sebagai gambaran bahwa penulis telah melakukan Riset/Penelitian di daerah Aceh Tengah Tepatnya di

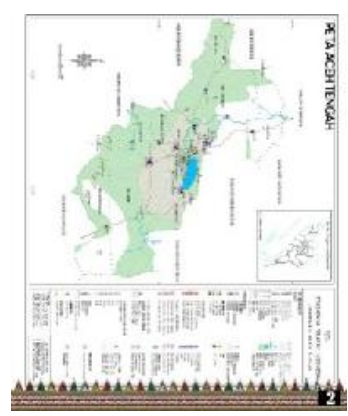
Kota Takengon yaitu Sanggar Renggali J1, Merah Mege, Hakim Balebujang, Laut Tawar Kabupaten

Hakim Balebujang, Laut Tawar Kabupaten Kota Aceh Tengah.

Penjelasan singkat letak

Riset/Penelitian penulis serta beberapa nama kota di kota Aceh Tengah.

\section{Sejarah Tari Guel :}
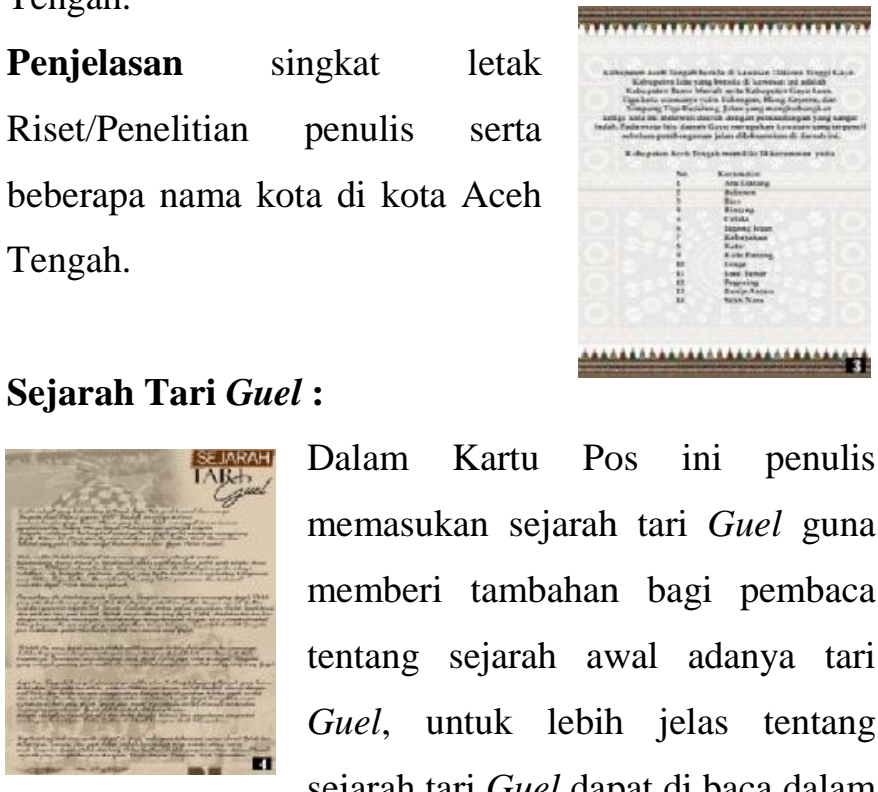

Dalam Kartu Pos ini penulis memasukan sejarah tari Guel guna memberi tambahan bagi pembaca tentang sejarah awal adanya tari Guel, untuk lebih jelas tentang sejarah tari Guel dapat di baca dalam

kartu pos yang sudah di kemas atau pada website www.wikipedia.com.

Sinopsis : Yaitu awal permulaan tari guel menceritakan sedikit kisah dan gerak awal sebelum dimulainya tari

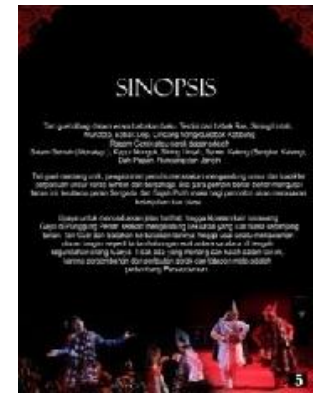

guel yang akan di pertunjukkan. Babak Ras Terbagi 4 :Gerdak, Papan, Semar Kalang, Kepur Nunguk, Jangin.

\section{Gerdak Papan :}

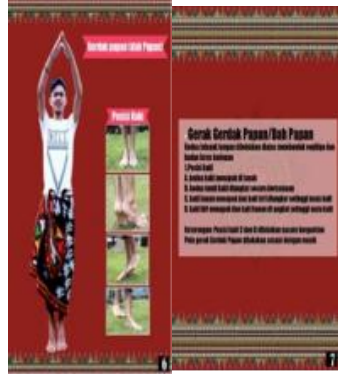

Gerdak Papan (Dah Papan) yang artinya menghentak papan sebagai gerakan pembuka dalam tari guel, penjelasan tari dapat dilihat pada halaman 7 dalam kartu pos.

\section{Ras (Semar kalang) :}

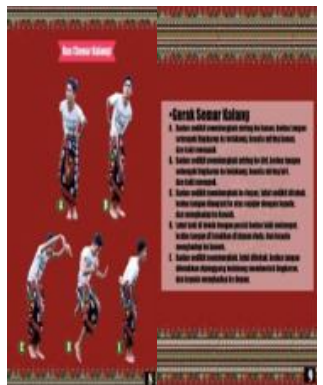

Ras artinya berlari Semar Kalang artinya Burung elang mencakar dalam gerakan ini penari seakan burung cakar yang berlari dan akan mencakar, penjelasan Gerakan ini dalam kartu pos.

\section{Kepur Nunguk :}

Kepur Nunguk artinya mengepakan sayap burung pungguk, gerakan ke tida dalam babak Ras, penjelasan

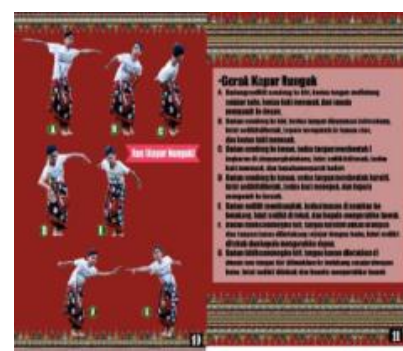
gerak dapat dilihat dalam kartu pos halaman 11 .

\section{Jangin :}

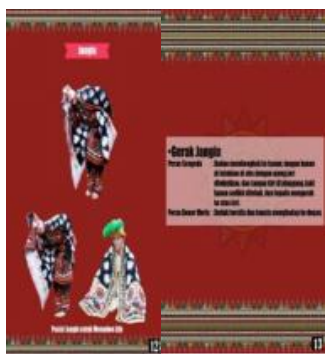

Jangin artinya memohon izin, penari memohon izin kepada penonton untuk melanjutkan tarian, dalam kartu pos ini 
gerakan jangin masuk kedalam gerakan terakhir dalam babak ras, penjelasan gerak dalam kartu pos.

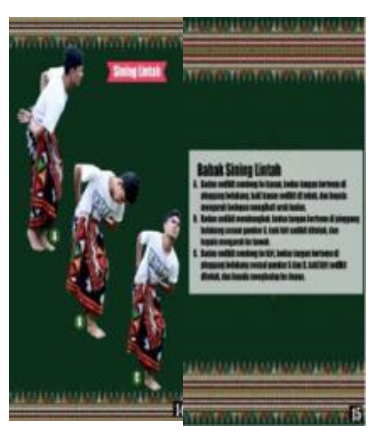

Babak Sining Lintah : Gerak Sining Lintah:

Sining Lintah artinya lintah berenang, pada ragam gerak ini penari memperagakan tarian meniru pergerakan lintah berenang, gerakan ini masuk kedalam babak Sining Lintah .

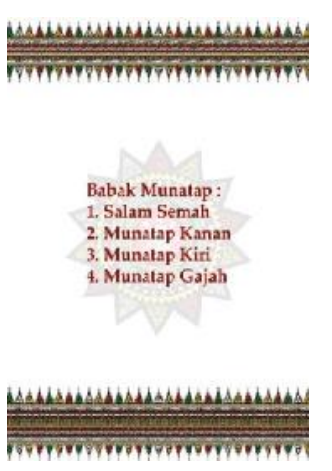

\section{Salam Semah:}

Salam Semah artinya yaitugerakan pertama

dalam babak Munatap,

\section{Babak Munatap:}

Salam Semah Munatap

Kanan Munatap Kiri

Munatap gajah

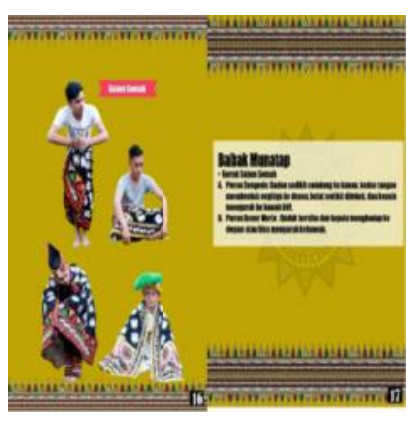

penjelasan gerak tari dapat di lihat didalam kartu pos halaman 17 .

Munatap Kanan : Munatap kanan artinya menatap ke

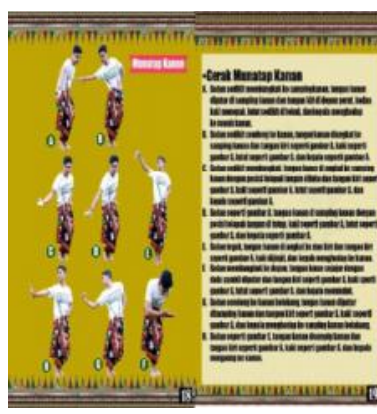
arah kanan, yang diiringi beberapa gerakan tangan dan kaki, gerakan kedua dalam babak Munatap, penjelasan gerak dapat dilihat dihalaman 19 dalam kartu pos yang sudah di

\section{Munatap Kiri :}

Munatap kiri artinya menatap ke arah kiri, yang diiringi beberapa gerakan tangan dan kaki, gerakan tiga dalam babak Munatap, penjelasan gerak dapat dilihat dihalaman 21 dalam kartu pos yang sudah di kemas
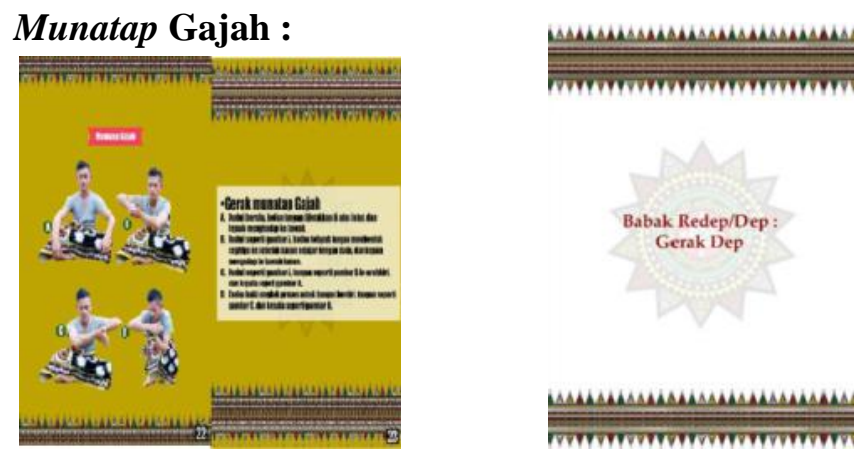

Munatap Gajah artinya bergerak seperti gajah, yang diiringi beberapa gerakan tangan dan kaki, gerakan empat dalam babak Munatap, penjelasan gerak dapat dilihat dihalaman 23 dalam kartu pos yang sudah di kemas.

\section{Babak Redep/Dep;}

Gerak Dep : artinya bergerak menghentakkan kaki ke tanah, gerakan ini masuk kedalam babak Redep/Dep, penjelasan gerak dapat dilihat dihalaman 25 didalam kartu pos yang sudah dikemas.
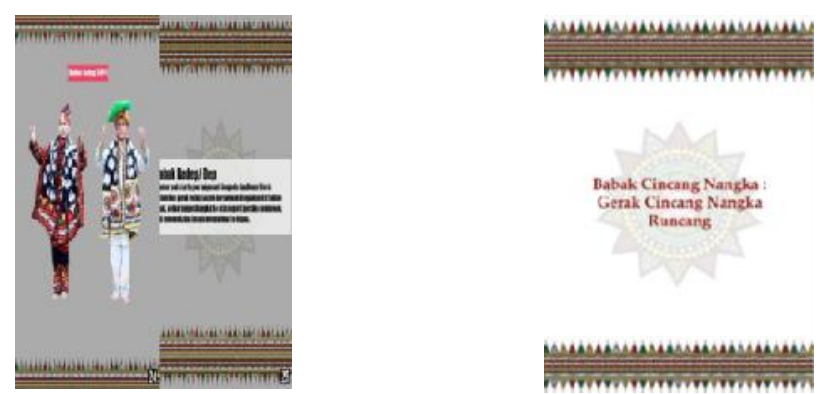

Babak Cincang nangka: Gerak Cincang Nangka

Runcang. Cincang Nangka:

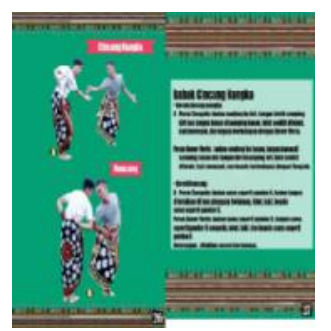


Runcang adalah gerakan yang dilakukan secara bersamaan dengan bebas.

\section{Babak Ketibung}

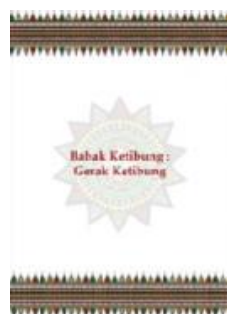

Gerak ketibung artinya masuk. Babak ketibung penjelasan gerak ini dapat dilihat didalam kartu pos yang sudah dikemas.

\section{Pertunjukan tari:}

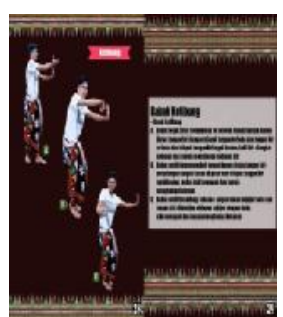

Tari guel yang di adakan di salah satu acara, tari guel merupakan tari pembuka atau tari perembahan sebagai pembuka acara, bahkan tari guel sudah mencapai kancah internasional.

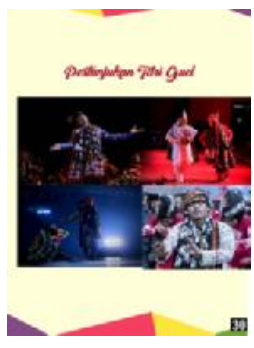

Pada halaman ke 31 penulis melampirkan foto rumah adat gayo, gunanya agar para pembaca dapat mengetahui juga tentang rumah adat gayo.

\section{Alat Musik Tari Guel}

Adapun beberapa alat musik sebagai pengiring tari guel adalah Canang, Gong, Gegedem dan Seruling. Busana Pemeran Sengeda. Penulis

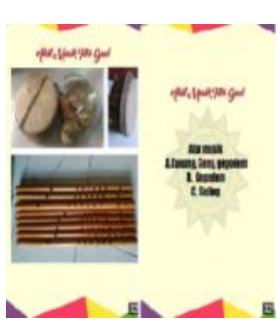
melampirkan juga busana yang di pakai oleh sengeda ketika penampilan tari guel, penjelsan busana dapat dilihat di dalam kartu pos.

Busana Pemeran bener Meria

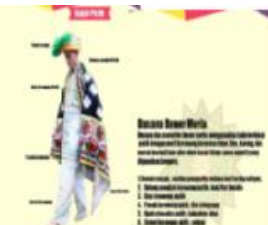
penulis melampirkan juga busana yang di pakai oleh Bener Meria ketika penampilan tari guel, penjelsan busana dapat dilihat di

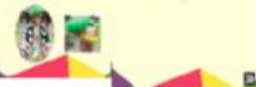
dalam kartu pos yang sudah dikemas.

Karakter yang dibuat penulis antara peran sengeda dan beuner meriah agar pembaca

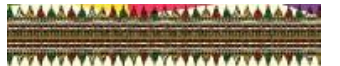
dapat membedakan peran diantara keduanya.

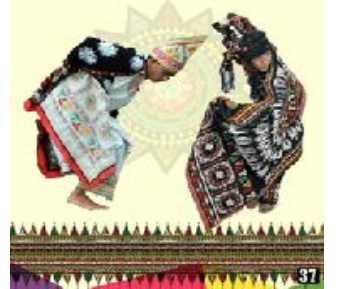
Glosary yang dibuat penulis bermanfaat agar pembaca dapat mengetahui makna dari bahasa Gayo. Riwayat hidup penulis dibuat agar pembaca mengetahui latar belakang pembuat kartu pos.

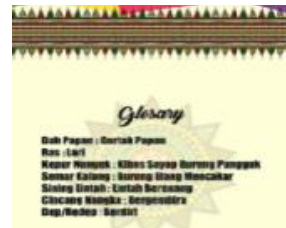

\section{PENUTUP}

\section{Kesimpulan}

Berdasarkan pada penjelasan-penjelasan sebelumnya, maka penelitian ini mengambil kesimpulan sebagai berikut.

1. Pengemasan tari Guel dalam bentuk kartu pos merupakan media visual dalam pembelajaran tari. 
2. Pengemasan tari Gueldalam bentuk kartu pos yang berisi ragam gerak, busana, alat musik, dan lain sebagainya.

3. Pengemasan tari Guel dalam bentuk kartu pos bertujuan untuk memudahkan guru supaya siswa lebih tertarik dengan mata pelajaran seni budaya khususnya seni tari.

4. Kartu pos yang dikemas dicetak dengan design yang menarik sehingga siswa mengingat materi yang diberikan.

\section{Saran}

Berdasarkan kesimpulan diatas, peneliti memberikan saran-saran sebagai berikut:

1. Guru mata pelajaran seni budaya khususnya pada mata pelajaran seni tari hendaknya menggunakan metode pembelajaran yang berbeda-beda dan tidak monoton sehingga siswa tidak bosan terhadap materi yang telah disampaikan.

2. Dengan adanya media visual berbentuk kartu pos sebagai media pembelajaran seni budaya dapat diaplikasikan oleh guru untuk meningkatkan minat siswa.

\section{DAFTAR PUSTAKA}

Aman Pinan Hakim, 2010. Pesona Tanah Gayo. Pemerintah Kabupaten Aceh Tengah.

Budiami, 2014. Skripsi Universitas Negeri Medan "Analisis Ragam Hias Gayo Pada Pakaian Tari Guel Di Takengon Kabupaten Aceh Tengah".

Cahyorini dan Rusfian, 2011. Pengemasan Produk. Jakarta : Bumi Aksara.

Ceriati, 2017. Skripsi Universitas Negeri Medan "Pengemasan Pembelajaran Tari Gubang Melalui Media Audio Visual Pada Siswa Kelas XI Sekolah Menengah Kejuruan (SMK) Negeri 5 Tanjung Balai”.
Desy Ari Natalia S, 2008. Skripsi Universitas Sumatera Utara. "Deskripsi Tari GuelPada Upacara Perkawinan Masyarakat Gayo Di Medan".

Gunawan, 2013. Metodologi Penelitian. Jakarta : Grafindo.

Hajar Ibnu, 2015. Membumikan Tari Guel Gajah Putih Bintang Dikarang. Sibuku Media.

Hartono, 2014. Metode Penelitian. Pekanbaru Zarafa Publishing.

Iskandar, 2008. Metode Penelitian Pendidikan. Bumi Aksara.

Kadir Ibrahim, 2015. Deskripsi Tari Guel. Sibuku Media

Narboko Cholid, 2008. Metodologi Penelitian. Jakarta : Bumi Aksara.

Nazir, 2003. Metode Penelitian Kualitatif. Jakarta : Bumi Aksara.

Nova Yanti, 2016. E-Jurnal Universitas Negeri Yogyakarta. "Pengemasan Tari Gambyong dan Tari Batara".

Sugandi, 2004. Dasar-dasar Pendidikan. Jakarta: Bumi Akasara.

Sugiono, 2008. Metode Penelitian Pendidikan. Bandung Alfabeta

Suharsaputra, 2014. Metodologi Penelitian. Yogyakarta: Gadjah Mada University Press.

Susilana dan Riyana, 2016. Media Pembelajaran. CV Wacana Prima Bandung.

Wiradnyana dan Setiawan, 2011. Merangkai Identitas Gayo. Jakarta : Yayasan Pusaka Obor Indonesia. 